\title{
Control potential of Heterorhabditis amazonensis (Rhabditida: Heterorhabditidae) in avocado borer, Stenoma catenifer (Lepidoptera: Elachistidae)
}

\author{
Vanessa Andaló ${ }^{*} \mathbb{D}$, Cleyton Batista de Alvarenga ${ }^{2}$, Renan Zampiroli ${ }^{2}$, Lucas Silva de Faria ${ }^{2}$, \\ Fábio Janoni Carvalho ${ }^{3}$, Naessa Naves ${ }^{2}$ \\ 10.1590/0034-737X201966020007
}

\begin{abstract}
Stenoma catenifer is considered the main pest of avocado, making impossible to commercialize the infested fruits. This study was conducted with the objective of evaluating the potential of Heterorhabditis amazonensis MC01 in the field control of avocado borer, as well as the nematode release method. Two treatments were tested, namely: release of dead Tenebrio molitor infected with the nematode and hydraulic nematode spraying; hydraulic application of chemical insecticides was used as a control. The experiment was set up in a randomized complete block design with 15 replicates. The concentration of suspension distribution was 5,500 infective juveniles per $\mathrm{m}^{2}$. At the experimental area traps with sex pheromone were installed to capture adult males. The number of borer fruits was evaluated in the two central plants of each plot, sampling 4 fruits per plant. There was a reduction in the percentage of borer fruits from 15 days of application for all control methods. After the release of nematodes, the adult population was similar to the control, and it can be inferred that, even without chemical control, there was no increase in the number of adults. Thus, H. amazonensis was considered promising under field conditions, reducing the populations of S. catenifer, in all release methods.
\end{abstract}

Keywords: avocado; biological control; entomopathogenic nematode; Persea.

\section{INTRODUCTION}

In Brazil, avocado is grown in almost all states due to the favorable edaphoclimatic characteristics that provide conditions for production throughout the year. Brazilian production is mainly distributed in the Southeast region, and the state of São Paulo is the largest producer. The Brazilian harvest in 2016 was approximately 180,636 t, of which 4,950,508 $\mathrm{kg}$ were destined for export, which represents almost $7 \%$ more in exports compared to the 2015 harvest (IBGE, 2016; Carvalho, 2017).

Avocado borer, Stenoma catenifer Walsingham (Lepidoptera: Elachistidae), is considered the main pest of avocado plantations, causing serious economic damage to the crop and, in many cases, leading to the abandonment of the production areas. Its presence leads to the reduction in production and makes the marketing of infested fruits unfeasible. Newly hatched caterpillars pierce the fruit epidermis by initially feeding on the pulp and forming galleries in the interior, and may subsequently reach the seed, depreciating the commercial value of the product (Hohmann et al., 2000; Nava et al., 2005a).

The newly attacked fruits have white spots due to external exudation and, with larval development, the fruit epidermis shows a deposit of excrements and food remains near the entrance hole of the caterpillar. In more severe attacks, several caterpillars can be found in a single fruit, leading, as a consequence, to its faster fall (Martinez \& Godoy, 1984). Damage caused by avocado borer varies depending on the cultivar, year, site and crop management, and there may be total losses (Hohmann \& Meneguim, 1993). Ventura et al. (1999) observed that 'Beatriz' is a cultivar more susceptible to the attack of borer in relation to 'Margarida', although both may show losses of

Submitted on February 18 $8^{\text {th }}, 2019$ and accepted on May 08 $8^{\text {th }}, 2019$.

${ }^{1}$ This work is part of a project developed in Universidade Federal de Uberlândia

${ }^{2}$ Universidade Federal de Uberlândia, Instituto de Ciências Agrárias, Monte Carmelo, Minas Gerais, Brazil. vanessaandalo@ufu.br; cleytonalvarenga@ufu.br; renanzampiroli@ufu.br; lucassilvafaria@hotmail.com; naessa_naves@outlook.com

3nstituto Federal do Triângulo Mineiro, Uberaba, Minas Gerais, Brasil. fjcarvalho1@gmail.com

*Correspondig author: vanessaandalo@ufu.br 
approximately $97 \%$ and $81 \%$, respectively, at the end of the cycle.

The main control method used is the chemical, and pyrethroids are commonly used (Hohmann et al., 2000), although there are no phytosanitary products registered in Brazil to control the pest. The lack of effective control measures makes it difficult to use integrated management and influences the increase in $S$. catenifer population in the field. As $S$. catenifer deposits its eggs directly on the fruits, the control strategies should be applied for a short time to obtain better control results, that is, from hatching until the penetration of first-instar larvae in the fruits (Hohmann et al., 2003), hindering pest control. Thus, the current situation shows the need for studies on pest control methods to establish an adequate management of $S$. catenifer in the avocado crop.

Entomopathogenic nematodes are considered promising biological control agents, particularly effective when applied to insects that inhabit or whose larval stage occurs in the soil (Dolinski et al., 2017). The use of these organisms to control $S$. catenifer pupae may be an alternative to pest management, considering that the pupae remain in the soil and that the perennial environment formed by the areas established with avocado favor the establishment of nematode populations. In Brazil, there are no established methods for the release of entomopathogenic nematodes. In this context, it is fundamental to analyze different methods that allow the distribution of the pathogenic agent in the field, besides being operational and economically viable in the crops.

Therefore, the objective of this study was to evaluate the potential of different methods of distribution of the entomopathogenic nematode Heterorhabditis amazonensis Andaló, Nguyen e Moino Junior, strain $\mathrm{MC01}$, in the control of $S$. catenifer pupae under field conditions, as well as to adapt the technology for the application of these organisms, in order to use them in a pest management plan.

\section{MATERIAL AND METHODS}

\section{Multiplication of entomopathogenic nematodes}

The nematode used in the experiment, H. amazonensis MC01, was isolated in Monte Carmelo, MG, Brazil. In order to obtain freshly emerged infective juveniles, the nematodes that were stored in a climatic chamber airconditioned room at $16^{\circ} \mathrm{C}$, were multiplied in Tenebrio molitor L. (Coleoptera: Tenebrionidae) larvae, reared as established by Potrich et al. (2007). Larvae dead by the nematodes were placed in a 9-cm Petri dish with filter paper for five days. Subsequently, distilled water was added to recover the emerged juveniles. Infective juveniles obtained up to three days after the onset of emergence were used.

\section{Characterization of the area}

For the field tests, an avocado planting area was used on Fazenda Pastão 3, located in Monte Carmelo region, MG, Brazil. The total area of the farm used for avocado planting is $60 \mathrm{ha}$, is located at an altitude of $1,020 \mathrm{~m}$, geographical coordinates $18^{\circ} 54^{\prime} 55.2^{\prime \prime} \mathrm{S}$, $47^{\circ} 21^{\prime} 43.7^{\prime \prime} \mathrm{O}$, located in the area of Planaltos e Chapadas da Bacia Sedimentar do Paraná, Southwest portion of the Brazilian Cerrado, in the mesoregion of the Triângulo Mineiro and Alto Paranaíba. According to the Köppen classification, the climate of this region is Cwa, temperature of $22{ }^{\circ} \mathrm{C}$ and rainfall of $1,500 \mathrm{~mm}$ (annual averages), and rains concentrated in six months, mostly in the summer period. The soil is predominantly clayey oxisol. The areas adjacent to the experiment facility have coffee and rubber plantations. The cultivation used has existed for 15 years and was constituted by cultivars Margarida and Geada, totaling an area of 6.0 ha, planted in spacing $6.0 \times 11.0 \mathrm{~m}$.

Due to the fact that it was a commercial crop, the following phytosanitary products were eventually used in the control area and in the adjacent areas: 1) fungicides: azoxystrobin + difenoconazole, captan, carbendazim, copper oxide, copper hydroxide, difenoconazole, sulphur, tebuconazole and thiophanato methyl; 2) insecticides/ acaricides: abamectin, acephate, Beauveria bassiana, beta-cyfluthrin, bifenthrin, carbosulfan, chlorpyrifos, clorantraniliprole, cypermethrin, fipronil, gamacyhalothrin, lambda-cyhalothrin, lufenuron, lufenuron + profenofos and novaluron; 3) herbicides: diquat dibromide, glyphosate, oxyfluorfen and paraquat dichloride. In addition, the parasitoid Trichogramma pretiosum Riley (Hymenoptera: Trichogrammatidae) was released in the avocado planting areas prior to the experiment setup.

\section{Control of Stenoma catenifer with entomopathogenic nematodes in the field}

The following treatments were tested: 1) manual release of dead T. molitor (obtained from 4 to 5 days) infected with nematodes; 2) hydraulic spraying with infective juveniles in the soil, below the canopy, and 3) hydraulic spraying of chemical insecticides (farm standard), considered the control. Fifteen replications were performed in a randomized block design, with each replicate containing a $25-\mathrm{m}$ line, with four plants. The nematode application concentration was standardized on 5,500 infective juveniles per $\mathrm{m}^{2}$. Thus, for the treatment with insect cadaver, 1 dead insect was released for every $10 \mathrm{~m}^{2}$, considering an average of 55,000 infective juveniles per dead insect.

For the treatment with hydraulic application of nematodes suspended in a 25-m line, 137,500 infective 
juveniles were sprayed. As a function of the length of the 2-m bar and the two sides of the bar $\left(2 \times 2=4 \mathrm{~m}^{2}\right)$, the application area was $100 \mathrm{~m}^{2}$ per line and a total area of $1,500 \mathrm{~m}^{2}$ (15 lines). A syrup volume of $500 \mathrm{~L} \mathrm{ha}^{-1}$ was used; thus, $100 \mathrm{~L}$ of syrup containing 2,062,000 infective juveniles were applied to $1525-\mathrm{m}$ lines. The sprayer Arbus $2000^{\circledR}$ was used, with horizontal bar adaptation and unilateral extension with an application range of $2 \mathrm{~m}, 3$ tips. The tips used were blue Magnojet ${ }^{\circledR}$ MDC-5, with an angle of $130^{\circ}$ and thick drops, according to the manufacturer. The working pressure was $114 \mathrm{kPa}$, and the application was performed in the morning, at a mean temperature of $20.3{ }^{\circ} \mathrm{C}$, relative humidity of $60.5 \%$ and wind speed of 5.4 $\mathrm{km} \mathrm{h}^{-1}$. The climatic data were obtained using an ITSP80001 thermo hygro anemometer.

The chemical treatment carried out in the area consisted in the application of the insecticides carbosulfan and novaluron, 30 days after experiment setup; lufenuron + profenofos, 45 days after experiment setup; and bifenthrin, 60 days after the experiment was set up.

In order to verify the number of borer fruits the two central plants of each replicate were evaluated, 4 fruits were sampled (one on each side), in the basal third of the plant (from 1.50 to $1.90 \mathrm{~m}$ in height). Evaluations of the number of individuals trapped and borer fruits were performed on the day of the experiment and then every 15 days for 90 days. The results were expressed as percentage of borer fruits and submitted to analysis of variance $(p<0.05)$ in a split plot scheme, and time was the subplot factor.

Viability and infectivity evaluations were performed for the treatment with infective juveniles applied with a horizontal bar sprayer. Therefore, aliquots of the suspensions were collected in three moments: in the preparation of the syrup, before being placed in the spray tank; in the first spray jet; and the last spray jet (obtaining a volume of about $10 \mathrm{~mL}$ in each collection). To verify the viability of the nematodes, ten $0.1-\mathrm{mL}$ aliquots of the suspension were taken for each application moment and 100 infective juveniles were observed under a stereoscopic microscope, counting the number of living and dead individuals.

Nematode infectivity was tested simultaneously with viability. $1 \mathrm{~mL}$ suspension was removed and pipetted into a Petri dish ( $9 \mathrm{~cm}$ in diameter) containing two filter papers per treatment. Each plate received 10 T. molitor larvae and was kept in a B.O.D. room at $25 \pm 1{ }^{\circ} \mathrm{C}, 70 \pm 10 \% \mathrm{RH}$ and $24 \mathrm{~h}$ dark for five days. Eight replicates were performed for each treatment. After this period, larval mortality was determined by nematodes, confirmed by the symptomatology characteristic of mortality caused by $H$. amazonensis. Viability and infectivity data were compared using the T-test for independent samples $(p<0.05)$.
For monitoring of adults in the experimental area, three Delta traps containing sex pheromone devices were installed to capture $S$. catenifer males. The traps were installed at $1.65 \mathrm{~m}$ from the soil, and the devices were changed every 60 days. Evaluations were performed every 15 days for 90 days. The population fluctuation of the adults was monitored for 8 months in order to verify the behavior of the insect over time.

\section{Permanence of entomopathogenic nematodes in the soil}

In order to verify the permanence of the nematode in the area, soil sampling was carried out every 30 days. The samples were collected at two points of each treatment (one in the first treatment line and another in the last line), totaling six samples. About $400 \mathrm{~g}$ of soil between 5 and $15 \mathrm{~cm}$ deep were removed, below the projection of the canopy of the avocado tree about $1 \mathrm{~m}$ from the stem. The samples were individualized in plastic bags and placed in a styrofoam box during transport from the collection area to the laboratory. The samples were labeled with the date of collection and the geographical coordinates.

The samples were divided into aliquots, which were processed by insect-bait isolation, constituted by a plastic container (14 x 14 x $7 \mathrm{~cm}$ ) with approximately $200 \mathrm{~g}$ of soil moistened with distilled water sterilized at $15 \% \mathrm{w} / \mathrm{v}$. Ten last-instar T. molitor larvae were added on the moist soil. The container was clodes and inverted ino order to the larvae stayed in the bottom. The mortality was evaluated after five days. The collections were made up to 90 days after the application of nematodes. On the day of the installation of the experiment, soil was collected to verify the possible previous existence of nematodes in the area before the release of $H$. amazonensis.

\section{RESULTS AND DISCUSSION}

\section{Control of Stenoma catenifer with entomopathogenic nematodes in the field}

In relation to the viability of entomopathogenic nematodes applied by sprayer (suspension treatment) in the experimental area, it was verified that there was a reduction in the viability of the infective juveniles and a reduction in the mortality of $T$. molitor between the time of preparation of the syrup and the beginning of the application. However, there was no difference between the beginning and end of spraying, considering that the time spent with spraying was 1 hour (Table 1). Even though there was a reduction in the viability of infective juveniles, the values obtained at the beginning and at the end of the application are considered satisfactory, since the majority of the nematodes remained alive. 
Entomopathogenic nematodes can be applied using a sprayer without loss of viability and infectivity when under a pressure of up to 1,379 MPa (Garcia et al., 2005, 2008),. In relation to the agitation of infective juveniles in the spray tank, Moreira et al. (2013) reported that no interference was observed in the survival of infective juveniles, and they were still capable of causing mortality in insects. Thus, the authors concluded that hydraulic spraying is a viable alternative for the application of entomopathogenic nematodes in the field. The same was observed in this study since, even though there was a reduction in viability and infectivity of infective juveniles over time, the mortality rates of the insects reached at the end of the application were considered satisfactory.

On the day of the installation, it was verified that the average percentage of borer fruits in the area was $20 \%$. According to the obtained data, it can be observed that there was a linear reduction in the percentage of borer fruits up to 90 days after the application of nematodes (Figure 1). However, there were no significant differences $(p>0.05)$ between the three control methods used, showing that both dead insect and spray application achieved similar controls to chemical treatment. It was observed that the treatments for the control of avocado fruit borer showed a marked reduction after 45 days and, at 90 days, the percentage of borer fruits reached $6.1 \%$. In this study, up to $70 \%$ reduction in the number of borer fruits was observed with the use of the proposed control measures. The results evidenced the control effect of the entomopathogenic nematodes on S. catenifer under the tested conditions, as well as their residual effect.

Hoddle \& Hoddle (2008) studied the attack level and damage pattern by $S$. catenifer in the field evaluating the proportion of borer fruits and also the number of holes per fruit in commercial 'Hass' avocado, and observed up to $45 \%$ of borer fruits through field evaluations. For the experiment setup, the nematoid was released when the average borer fruit in the area was $20 \%$, a value that was already causing a reduction in yield due to fruit fall and making them commercially infeasible.

As for the evaluation of the presence of adults in the Delta traps with sex pheromone, it was verified that, in experiment setup, the initial population of insects found in the traps was of 9 adults in the control area, 6 adults in the treatment area with the release of deadinsects and 3 adults in the hydraulic spraying treatment (Figure 2).

Table 1: Viability of Heterorhabditis amazonensis MC01 and mortality of Tenebrio molitor applied in the field for the control of Stenoma catenifer before, in the beginning and at the end of spraying. Pastão 3 Farm, Monte Carmelo, MG, Brazil. Average temperature of $20.3{ }^{\circ} \mathrm{C}$ and relative humidity of $60.5 \%$.

\begin{tabular}{lcc}
\hline Time of application & $\begin{array}{c}\text { Viability of infective } \\
\text { juveniles }(\boldsymbol{\%}) *\end{array}$ & $\begin{array}{c}\text { Mortality of Tenebrio } \\
\text { molitor }(\boldsymbol{\%}) *\end{array}$ \\
\hline Before application (preparation of the syrup) & $99.5 \pm 0.75 \mathrm{a}$ & $90.0 \pm 7.56 \mathrm{a}$ \\
Beginning of spraying (1st jet) & $85.7 \pm 4.74 \mathrm{~b}$ & $81.3 \pm 6.41 \mathrm{~b}$ \\
End of spraying (last jet) & $85.7 \pm 4.23 \mathrm{~b}$ & $80.0 \pm 7.56 \mathrm{~b}$ \\
\hline
\end{tabular}

* Means followed by the same letter in the column do not differ by the T test $(p<0.05)$. Mean $\pm \operatorname{SD}(\mathrm{M})$.

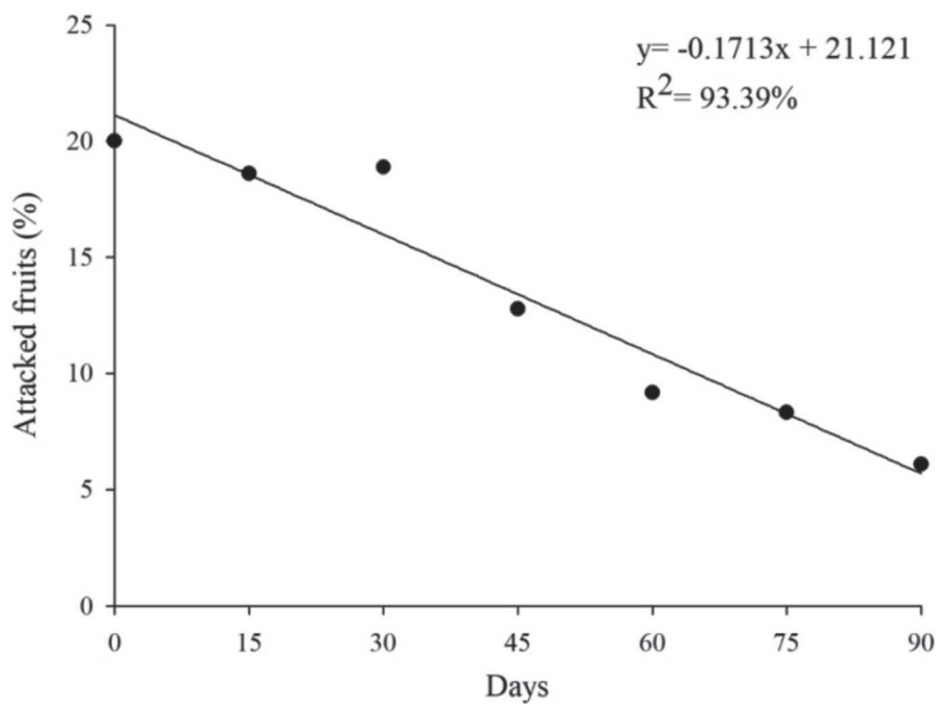

Figure 1: Avocado fruit borer by Stenoma catenifer over time. Pastão 3 Farm, Monte Carmelo, MG, Brazil. 
Considering that the action of the nematode on the adult population can be observed after 15 days of application, it was observed that, at 15 and 90 days of evaluation, 6, 15 and 14 adults and 16, 23 and 19 adults were captured in the treatments with hydraulic spraying, insect cadaver and control, respectively. Thus, observing the difference in the number of individuals captured at these times, 10 adults were obtained for the suspension treatment, 8 adults in the treatment with insect cadaver and 5 adults in the control. Thus, it can be observed that the adult population in the treated area was similar to that found in the control as a function of the final values of adults caught in the traps (Figure 2). Therefore, the use of nematodes was considered as effective as the insecticide, when related to the population fluctuation of $S$. catenifer adults in the evaluation period of the experiment.

In relation to the population dynamics of adults it was verified that there was a variation in the number of adults captured during eight months. 30 days after the release of the nematodes, there was a reduction in adult capture and, at 45 days, the number of collected individuals decreased and was balanced until the end of the evaluation at 90 days (Figure 3).

Considering that the life cycle of $S$. catenifer has a mean of 35 days, a pupal period of 15 days (Nava et al., 2005a) and the control target is the pupae, it can be considered that the effect of the nematodes in adults can be observed from 15 days of release and the presence of caterpillars in the fruits only in the following borer generations.
According to Castillo et al. (2012) and Vázquez et al. (2017), captures of $S$. catenifer males attracted by the sex pheromone using traps occur mainly when flowering begins and is associated with the presence of fruits in the field. For the execution of this study, fruits were maintained in the plants during the whole evaluation period once, on the farm, the selective collection of the fruits is carried out, that is, only the fruits considered suitable for commercialization were collected the plants. Thus, the gradual increase in the number of adults collected in the treatments and the control after 90 days of evaluation may be associated with the constant presence of fruits in the field and the occurrence of subsequent generations of the insect.

It was also possible to observe that in the treatment with the nematodes released in insect cadaver the reduction in trapped adults was slower, decreasing the amount of adults only after 45 days, whereas in the control and the suspension treatment, this reduction was observed at 30 days (Figure 3 ). This result can be explained as a function of the time the infective juveniles took to emerge from the insect cadaver which could take up to five days, while in suspension treatment, the infective juveniles were applied directly to the soil, ready to search for the host.

The studies conducted on $S$. catenifer refer mainly to the use of sex pheromones for adult monitoring and insect bioecology; however, little has been discussed about pest control, and these studies are limited to the use of parasitoids such as Trichogramma and Trichogrammatoidea and control by fruit bagging (Nava

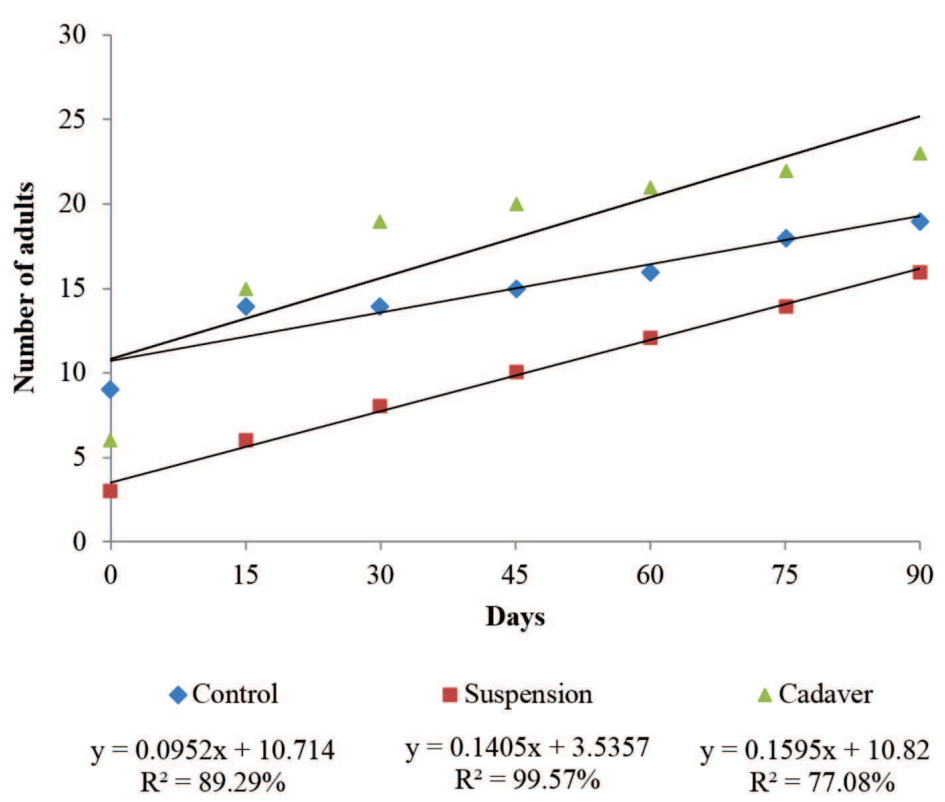

Figure 2: Cumulative number of Stenoma catenifer adults collected in Delta traps with sex pheromone over 90 days. Pastão 3 Farm, Monte Carmelo, MG, Brazil.

Rev. Ceres, Viçosa, v. 66, n.2, p. 124-131, mar/abr, 2019 


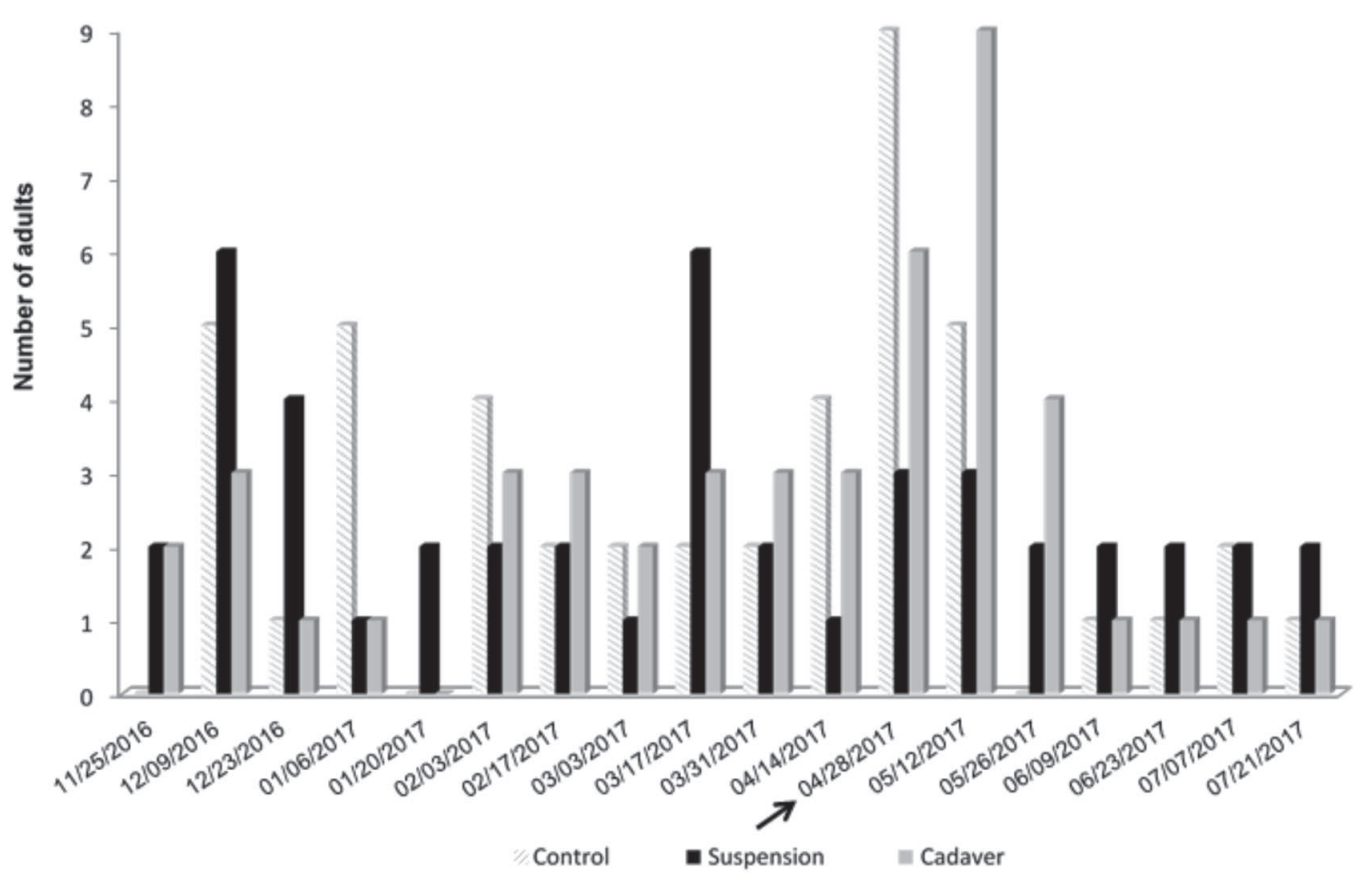

Figure 3: Population fluctuation of Stenoma catenifer adults collected every 15 days in Delta traps with sex pheromone from November 2016 to July 2017. Pastão 3 Farm, Monte Carmelo, MG. The arrow indicates the application date of Heterorhabditis amazonensis MC01.

et al., 2006; Nava et al., 2007; Castillo et al., 2012; Hoddle et al., 2011).

Studies testing entomopathogenic nematodes with lifecycle insects similar to $S$. catenifer have been conducted, as that developed by Simi et al. (2018), who tested Steinernema brazilense Nguyen, Leite, Ginarte, Leite, Santos, Harakava in the control of cupuaçu borer, Conotrachelus humeropictus (Fiedler) (Coleoptera: Curculionidae), causing $60 \%$ larval mortality. The fourth instar larvae of this insect remains in the soil, becoming a target for the action of entomopathogenic nematodes, the same site where $S$. catenifer pupae remains.

Silva et al. (2010) tested the nematode Heterorhabditis indica Poinar, Karunakar, David IBCB n5 for the control of guava weevil, Conotrachelus psidii Marshall (Coleoptera: Curculionidae), a species that, as $S$. catenifer, spends part of its life cycle in the soil, in this case prepupae, pupae and adult, being considered a pest of difficult control. The nematode was applied at a dosage of $10 \mathrm{I} / \mathrm{cm}^{2}$ and $50 \%$ mortality rates were achieved.

\section{Permanence of entomopathogenic nematodes in the soil}

As for the verification of the entomopathogenic nematodes in the soil before the experiment installation, no populations were found in the sampled areas. After 30 days of the experiment, nematodes were isolated by the insect-bait technique in areas with juvenile release in the form of insect cadaver and suspension application, and no nematodes were found in the control area. The same was observed over time until the evaluation of 90 days, where nematodes were still found in the soil in the treated areas; it was found that the juveniles remained viable and infective in the treated areas over time.

Considering pest management, nematodes will act in one of the phases where the insect remains in the soil since, when they are about to become pupae, the caterpillars abandon the fruits and migrate to the soil under leaf debris, leaving the pupae to a depth of 0.5 to $1.5 \mathrm{~cm}$, or within fallen fruits for approximately 15 days (Hohmann et al., 2000). In this environment, the pupae become potential targets for the action of the infective juveniles that remain in the soil in search of a host.

Limiting factors for the permanence of entomopathogenic nematode populations are associated with ultraviolet light irradiation rates and soil water availability. Ground or decaying vegetation cover favors the soil moisture, which is an ecosystem that favors the presence and persistence of nematodes (Wilson \& Gaugler, 2004). Thus, the environment provided by avocado plants creates favorable conditions for the nematodes to remain in the soil, which may favor the control of $S$. catenifer for an extended period, allowing inoculative releases of infective juveniles.

Valle et al. (2008) studied the action of Heterhorhabditis baujardi LPP7 Phan, Subbotin, Nguyen, Moens, under C. psidii, by the release of dead Galleria mellonella L. (Lepidoptera: Pyralidae) insects 
under field conditions and verified the persistence of the nematode in the field for up to six weeks after application, but observed that, after 12 weeks, a gradual reduction occurred in the presence of $H$. baujardi in the soil.

Alternatives in the control of $S$. catenifer are fundamental to reduce the population of the pest in the field, mainly due to the difficulty in the control and use of unregistered chemical insecticides, which causes the emergence of secondary pests and cases of resistance to insecticides (Nava et al., 2005b, 2006). Based on the results obtained in this study, the use of $H$. amazonensis MC01 can be considered as a potential tool in the control of pupae in the soil, in order to increase the control of $S$. catenifer in the avocado crop.

\section{CONCLUSIONS}

The hydraulic spraying system did not interfere with the viability and infectivity of $H$. amazonensis MC01. There was a reduction in these parameters between the preparation of the syrup and the beginning of the application.

There was a reduction in the number of borer fruits adults in the areas treated with entomopathogenic nematodes for both insect cadaver and suspension forms. The capture of adults in traps with sex pheromones in the treatments showed the same distribution pattern as in the control.

The reduction in adults trapped in the treatment with insect cadaver occurred after 45 days, while in the control and in the suspension treatment, after 30 days.

Heterorhabditis amazonensis MC01 was considered promising in the control of $S$. catenifer when released in suspension and through the insect cadaver under the tested conditions.

\section{ACKNOWLEDGEMENTS}

The authors thank to Iwao Mamose Group for the experimental area and also to the Conselho Nacional de Desenvolvimento Científico e Tecnológico (CNPq) and Fundação de Amparo à Pesquisa do Estado de Minas Gerais (FAPEMIG) for financial support.

\section{REFERENCES}

Carvalho C (2017) Anuário Brasileiro da Fruticultura. Santa Cruz do Sul, Editora Gazeta Santa Cruz. 88p.

Castillo A, Cruz-Lopez L \& Gómez J (2012) Moth species captured with the sex pheromone of Stenoma catenifer (Lepidoptera: Elachistidae) in avocado plantations of southern Mexico. Florida Entomologist, 95:1111-1116.

Dolinski C, Monteiro C, Andaló V \& Leite LG (2017) Studies on entomopathogenic nematodes in Brazil: past and future. Nematoda, 04:102017.
Garcia LC, Raetano CG, Wilcken SRS, Ramos HH, Leite LG, Filho AB \& Moscardi F (2005) Pressurização da calda de pulverização na viabilidade de microrganismos entomopatogênicos. Engenharia Agrícola, 25:783-790.

Garcia LC, Raetano CG \& Leite LG (2008) Application technology for the entomopathogenic nematodes Heterorhabditis indica and Steinernema sp. (Rhabditida: Heterorhabditidae and Steinernematidae) to control Spodoptera frugiperda (Smith) (Lepidoptera: Noctuidae) in corn. Neotropical Entomology, 37:305-311.

Hoddle MS \& Hoddle CD (2008) Bioecology of Stenoma catenifer (Lepidoptera: Elachistidae) and associated larval parasitoids reared from Hass avocados in Guatemala. Journal of Economic Entomology, 101:692-698.

Hoddle MS, Millar JG, Hoddle CD, Zou Y, McElfresh JS \& Lesch SM (2011) Field optimization of the sex pheromone of Stenoma catenifer (Lepidoptera: Elachistidae): evaluation of lure types, trap height, male flight distances, and number of traps needed per avocado orchard for detection. Bulletin of Entomological Research, 101:145-152.

Hohmann CL \& Meneguim AM (1993) Observações preliminares sobre a ocorrência da broca do abacate, Stenoma catenifer Wals. no Estado do Paraná. Anais da Sociedade Entomológica do Brasil, 22:417-419

Hohmann CL, Meneguim AM, Andrade EA, Novaes TC \& Zandoná C (2003) The avocado fruit borer Stenoma catenifer (Wals.) (Lepidoptera: Elachistidae): egg and damage distribution and parasitism. Revista Brasileira de Fruticultura, 25:432-435.

Hohmann CL, Santos WJ \& Meneguim AM (2000) Avaliação de técnicas de manejo para o controle da broca-do-abacate, Stenoma catenifer (Wals.) (Lepidoptera: Oecophoridae). Revista Brasileira de Fruticultura, 22:359-363.

IBGE - Instituto Brasileiro de Geografia e Estatística (2016) Produção agrícola municipal. Disponível em: https:// sidra.ibge.gov.br/tabela/1613\#resultado. Acessado em: 20 de setembro de 2018 .

Martínez NB \& Godoy FJ (1984) Observaciones preliminares sobre la biologia de Stenoma catenifer Walsingham (Lepidoptera: Stenomidae) taladrador del aguacate (Persea americana Mill). Agronomía Tropical, 34:205-208.

Moreira GF, Batista ESP, Campos HBN, Lemos RE \& Ferreira MC (2013) Spray nozzles, pressures, additives and stirring time on viability and pathogenicity of entomopathogenic nematodes (Nematoda: Rhabditida) for greenhouses. Plos One, 08:657-659.

Nava DE, Haddad M de L \& Parra JRP (2005a) Temperature requirements, estimate of the generations number of Stenoma catenifer and verification of the model in the field. Pesquisa Agropecuária Brasileira, 40:961-967.

Nava DE, Parra JRP, Costa VA, Guerra TM \& Cônsoli FL (2005b) Population dynamics of Stenoma catenifer Walsinghan (Lepidoptera: Elachistidae) and related larval parasitoids in Minas Gerais, Brazil. Florida Entomologist, 88:441-446.

Nava DE, Parra JRP, Bento JMS, Rodríguez GID \& Haddad M de L (2006) Distribuição vertical, perdas e controle cultural de Stenoma catenifer Walsingham (Lepidoptera: Elachistidae) em pomares de abacate. Neotropical Entomology, 35:516-522.

Nava DE, Takahashi KM \& Parra JRP (2007) Linhagens de Trichogramma e Trichogrammatoidea para controle de Stenoma catenifer. Pesquisa Agropecuária Brasileira, 42:09-16.

Potrich TD, Lorini I, Voss M, Steffens MCS \& Pavani DP (2007) Metodologia de criação de Tenebrio molitor em laboratório para obtenção de larvas. Passo Fundo, Embrapa Trigo. 01p. (Boletim Técnico, 82).

Rev. Ceres, Viçosa, v. 66, n.2, p. 124-131, mar/abr, 2019 
Silva AC da, Batista Filho A, Leite LG, Tavares FM, Raga A \& Schmidt FS (2010) Efeito de nematoides entomopatogênicos na mortalidade da mosca-do-mediterrâneo, Ceratitis capitata, e do gorgulho-da-goiaba, Conotrachelus psidii. Nematologia Brasileira, 34:31-40.

Simi LD, Leite LG, Trevisan O, Costa JNM, Oliveira LE, Schmidt FS, Bueno RNS \& Batista Filho A (2018) Mortality of Conotrachelus humeropictus in response to combined application of the nematod. Arquivos do Instituto Biológico, 85:01-09.

Valle EE del, Dolinski C, Barreto E, Souza R \& Samuels R (2008) Efficacy of Heterorhabditis baujardi LPP7 (Nematoda: Rhabditida) applied in Galleria mellonella (Lepidoptera: Pyralidae) insect cadavers to Conotrachelus psidii, (Coleoptera: Curculionidae) larvae. Biocontrol Science and Technology, $18: 33-41$
Vázquez MA, Cruz-López L, Gómez J \& Castillo A (2017) Annual capture of two elachistidae moth species using Stenoma catenifer sex pheromone in criollo avocado (Persea americana) at Chiapas, Mexico. Southwestern Entomologist, 42:91-101.

Ventura MU, Destro UD, Lopes ECA \& Montalván R (1999) Avocado moth (Lepidoptera: Stenomidae) damage in two avocado cultivars. Florida Entomologist, 82:625-630.

Wilson M \& Gaugler R (2004) Factors limiting short-term persistence of entomopathogenic nematodes. Journal of Applied Entomology, 128:250-253. 